\title{
The Study of EFL Students' Requests Based on Politeness Theory
}

\author{
Azadeh Elmianvari \\ Department of Linguistics, Ghent University, Ghent, Belgium \\ Reza Kheirabadi \\ Organization for Educational Research and Planning (OERP), Tehran, Iran
}

\begin{abstract}
This study is carried out to see if the politeness theory proposed by Brown and Levinson (1987) is applicable to data elicited from EFL students attending a language institute in Iran. Students were asked to email their teacher as a class activity and make a request in an appropriate and polite form. Different viewpoints regarding the status of request in politeness perspective and also student-teacher relation in language classrooms in Iran were discussed. Based on Holtgravesand Yang's (1992) coding scheme, email requests were analyzed and the result showed that apart from a few emails almost all the requests could be cinsidered as polite and just two of them located somewhere in the middle of scale of politeness. Since the analysis is not an absolute objective one, we can conclude that most of the students expressed their requests in a polite, formal and indirect way through long sentences as an attempt to save the negative face.
\end{abstract}

Index Terms — politeness theory, face, face threatening act, request, imposition

\section{INTRODUCTION}

According to Norris (2001), learners of another language need to learn sociolinguistic norms of language behavior, politeness strategies of the target language and the ability to appropriately use these rules in communication.

This research was aimed at determining to what extend data from Iranian EFL students' email requests are based on the politeness theory. Academic student-professor emails were the activities which manifest requests. Through a precise coding system, the politeness strategies of the participants' requests were explored.

Statement of the problem

Iranian learners of English interact with very few foreigners because of the current political status; there is absolutely no general need to communicate properly with English speakers that are not familiar with the Persian language and culture. In most EFL situations learners have specific needs, like applying for a job at a foreign company or talking to a foreign professor at the university. The most interactive exposure of language learners to native speakers in Iran is through movies. Most language learners do not exploit the internet for such purposes. University students in particular use the English portion of the internet or article searching for university projects. The Persian portion of the net however, has become a main channel of communication and interaction amongst Farsi-speaking people throughout the world. Chat rooms and weblogs are exploding with members posting and waiting for comments and messages every day. So, to say that the Iranian community doesn't use the internet would be completely false. The extent of which the Iranian community makes use of the English portion of the internet is questionable however. Thus an immediate need must be created for the community of Iranian language learners.

One way to create such a need is to enforce a rule that the students must ask their questions via email and their professors could refer them to a certain text or answer them also via email. For this to happen, there are many preliminary steps involved. Professors must have access to the Internet on campus, they must be trained how to use the system efficiently, there should be a webpage for each professor to post general questions publicly so he or she will only have to answer each question once. That would be a really demanding task because as an attending graduate student, I have emailed a professor only to get an oral response twenty days later asking what the email was about. The example was mentioned to show the extent of artificiality of email in the academic context of Iran.

\section{REVIEW OF THE RELATED LITERATURE}

In this study, e-mail has been chosen as a form of computer-mediated communication. It promotes interactive language learning and the opportunity for authentic use of the target language (Chun, cited in $\mathrm{Li}, 2000$ ). It also serves to foster student empowerment (Warscauer, cited in $\mathrm{Li}, 2000$ ). It is used in hope of motivating the students and promoting the functional use of second language.

Gonglewski, Meloni, and Brant, 2001 discuss the pedagogical benefits of using email in EFL classrooms. The following are some of the benefits they mention: Extending language learning time and place, providing a context for real-world communication and authentic interaction, expanding topics beyond classroom-based ones, promoting 
student-centered language learning, and encouraging equal opportunity participation. Specifically in regard to email between the teacher and the foreign language learner, they believe that the learner gains self-assurance along with experience using electronic media in the foreign language.

According to the article, the most important benefit of email in an EFL classroom is "potential to offer learners opportunities for much more valuable communicative interaction in the target language than was ever possible in the traditional foreign language classroom." (Gonglewski, Meloni and Brant, 2001, p.13). Speech acts and pragmatics are part of exactly such "valuable communicative interaction" which needs to be focused on particularly in EFL contexts. Email is a medium through which much can be explored and learned.

What are speech acts?

Searle (1969, cited in Schmidt 1994, p.4) believes: "speaking a language is performing speech acts, acts such as making statements, giving commands, asking questions, making promises... these speech acts are the basic or minimal units of linguistic communication." Speech acts are the set of realization patterns typically used by native speakers of the target language, any one of which would be recognized as the speech act in question, when uttered in the appropriate context (Olshtain \& Cohen, 1983, cited in Cohen, 2004). Speech acts are those patterned, routinized phrases used regularly to perform a variety of functions such as requesting, refusing, complimenting, greeting, thanking and apologizing (Cohen, 2004).

For thirty years, language educators have been trying to teach second language learners; not just the form of speech acts but also their place in speech and the combination of them with other speech acts. Learning speech acts is of great importance. Cohen (2004, p.3) mentions: "Learners of a language can have all of the grammatical forms and lexical items and still fail completely at conveying their message because they lack necessary pragmatic or functional information to communicate their intent." Unfortunately in Iran, many language schools see teaching grammar as the main goal of their curriculum. They add so-called communicative tasks to liven the class up.

Requests were selected to be investigated because of its direct relation to politeness theories and the cultural issues attached to requests. Within the universals of politeness, every language and culture has its own politeness configurations. Offering (help, for example) before the person requests it, repeatedly refusing offers before accepting, and not declining requests (even if they are out of the person's range of doing them) are highly valued in the Iranian culture. Another reason is that students -as participants- have the potential to encounter requests more than other speech acts (e.g. complaining or apologizing).

Research in the field of requests in the form of academic emails has been carried out, the earliest of which is probably the study done by Hartford and Bardovi-Harlig in 1996. Hartford and Bardovi-Harlig (1996) analyzed perlocutionary affect e-mail requests sent by NS and NNS graduate students to professors. They concluded that, in general, NNS e-mails did not adequately address imposition, which negatively affected perlocution. In addition, NNS messages consisted of fewer downgraders and other mitigating supportive moves such as grounders and apologies, which negatively affected the impact of the requests.

Ford (2003) refers to a line of research into linguistic variation in written e-communication that has possible implications for pragmatics research if it can be shown that different pragmatic strategies are required to successfully communicate in different electronic environments for different purposes. He cites Gaines (1999) who studied a large corpus of business and academic e-mails and concluded that the academic data contained evidence of new written genres with unique textual features. Lan (2000) is also cited by Ford (2003) for examining and comparing e-mail messages from two universities, one in Hong Kong and one in England. The research concluded that formal, semiformal, and friendly e-mail messages from both NSs and NNSs of English all contain varying degrees of conversational style.

In the academic field relatively few studies have analyzed cross-cultural differences in e-communication. Chen (2001) analyzed and compared e-mail requests sent by Taiwanese and U.S. graduate students to their professors. She claims that the Taiwanese students used different request strategies than the U.S. students due to culturally different perceptions of power relations, familiarity, and imposition. This study helps shed some light on written ecommunication strategies used by students from different cultural backgrounds.

Ford (2003) claims that results in the area of email pedagogy indicate that student language use strategies through email communication vary considerably according to perceived formality of the e-mail task and depending on whether or not the task involves an actual audience with an exchange of dialog. Chen (2001) illuminates the possibility of divergent culture-specific pragmatic strategies employed by even advanced-level ESL students when making e-mail requests in the academic setting.

Kankaanranta (2001, cited in Ford 2003) reported that Finnish and Swedish colleagues of one European company showed significant differences across first language groups in their use of politeness strategies in English e-mail messages. She found that her subjects prefer imperative and interrogative request forms, which can negatively affect politeness and increase the threat to the hearer's face.

According to research done by Ford (2003) there are patterns in the development of e-communication pragmatics, strategies, and usage, corresponding to academic level and university education experience in an English setting. His research showed tendencies of his subject groups, which may imply general knowledge of the use of certain pragmatic 
features to attain locutionary intents, and inform pedagogy about possible focuses of instruction in the area of ecommunication.

Politeness Theory

Based on earlier work on 'face' by Goffman (1955) Politeness theory was presented by Brown and Levinson (1987). To answer the question of why the most direct and the clearest way of speaking is not always chosen in people's social interactions, Brown and Levinson proposed that face has two aspects: negative and positive. Negative face is defined as "the want of every competent adult member that his actions be unimpeded by others" (Brown and Levinson, 1987: 62) and "want to have his freedom of action unhindered and his attention unimpeded" (129). Positive face is defined as "the want of every member that his wants be desirable to at least some others" (62) and "perennial desire that his wants (or the actions/ acquisitions/ values resulting from them) should be thought of as desirable" (101). In other words, people are motivated by these two desires or needs: to remain autonomous or independent and to be approved or connected to others.

Goffman's viewpoint about the speaker whom put himself in danger in the process of interaction, was the basis for the concept of face threatening act in Brown and Levinson's theory (1978). To maintain their own face, people save other people's positive or negative face in an interaction. On the other hand starting a conversation including suggestions, requests, or criticism is inevitable. Thus, According to politeness theory, any statement that threatens other people's face is considered a face threatening act. Based on Brown and Levinson's view, face threatening acts can appear in all of the interactions and to redress the effect of theses possible threats, "mitigation strategies" or politeness strategies are used. Duthler (2006), clarifies the notion through an example:

If a student need to meet a professor to discussed a concept out of office hour, based on politeness theory, the request threatens the professor's negative face because it endanger the professor's desire to be left alone. In the process of making a request students can choose among various actions. the student can simply make the request Baldly or On Record in the imperative and most direct way (e.g., "Meet with me!"); the student can express affinity by making the request using Positive Politeness ("Let's meet to discuss your ideas."); the student may minimize the imposition by making the request with Negative Politeness ("Would you be willing to meet with me for just a minute about this concept?"); the student can make an Off-Record request by hinting or using ambiguous language to minimize the threat ("Usually when I talk through a concept, I can understand it better"); or the student may not make the request at all.

Therefore, each person chooses a strategy based on the seriousness of the face threatening act. The speaker estimates the social situation and accordingly chooses a strategy. According to Brown and Levinson, some factors are important in this selection process: degree of imposition, power relation and social distance.

The degree of imposition of face threatening act defined as "a culturally and situationally defined ranking of impositions by the degree to which they are considered to interfere with an agent's wants of self-determination or of approval (negative and positive face wants)" , is evaluated by the speaker (p. 77). Some impositions are greater than others. Highly imposing acts like requests need more redress to soften their increased threat level. The elative power of the hearer over the speaker, defined as "the degree to which the hearer can impose his own plans and his own selfevaluation (face) at the expense of the speaker's plans and self-evaluation" is considered by the speaker (p. 77). In a given situation the speaker speaks differently with those who are socially equal to him and those with higher or lower status.

The speaker evaluates the social distance between the speaker and the hearer which is defined as the "symmetric social dimension of similarity/difference within which the speaker and hearer stand for the purpose of an act, and can refer to the frequency of interaction and the kinds of goods exchanged between the speaker and the hearer" (p. 77). In other words the speaker distinguishes a friend from a stranger who is at the same social status with the speaker but still is separated by social distance. For example in speaking with family, a speaker may choose a positive rather than a negative politeness.

Brown and Levinson's theory has received criticism mostly because of it pessimistic nature that sees all interactions as face threatening acts and fundamentally dangerous. According to Nwoye (1992:311, cited in koutlaki, 2002) "if the view of constant potential threat to the interlocutors' faces is always true, It could rob social interaction of all elements of pleasure". Ethnocentricity in Brown and Levinson's viewpoint is another factor that account for the criticisms mostly from non-western languages. In their work on Japanese politeness, Matsumoto (1988) and Ide (1989) cited in koutlaki, (2002), have criticized Brown and Levinson's work that cannot explain their data since it is based on "Western ideals of each individual's value and territorial rights". Similarly, researches done by Gu (1990) and Mao (1994) cited in koutlaki (2002) on Chinese, have shown that the Chinese face is different from Brown and Levinson's model and challenges its universality.

Regarding the concept of request which is the main issue in this research and the status of request in Iranian community in particular, two opposing views were discussed in the literature.

The request is considered as a highly imposing act by Brown and Levinson. On the contrary, a study by Koutlaki (2002) which describes some aspects of social organization in Iranian society and analyzes Persian face, express the idea that in Iranian community as well as some non-western cultures, requests are not considered as face threatening acts: 
The concept of negative face threatening acts in Brown and Levinson's model does not seem right for Iranian culture. In the same situation, offering for instance, does not put the freedom of hearer in danger and threaten the negative face. In Brown and Levinson's description of face, the "individual's self-image" is taken into consideration while in a nonwestern language like Persian, the face is public based, in other words it is oriented towards "an ideal social identity". In such community the anti social behavior causes embarrassment both to the person and also more importantly, to the group to which he belongs and group interest is every member's priority. Therefore the exchange of services is part of everyday life in this society and request is not considered a face threatening act by the members of this group. Politeness is then considered as an expected behavior among the members of society and the commitment to that behavior is socially contracted. The analysis seems to be true but, the idea cannot be applicable to all sample community in Iranian society.

Regarding the power relation in language classroom the teacher's knowledge determines the dominant position of the teacher over the students. The teaching is monolingual and the relation between the teacher as the "all-knowing" authority and the students as the individuals who are doomed to listening is unidirectional. The teacher is responsible for delivering the knowledge and has all the unquestioned power in conversation: the authority of deciding the conversation topics, class activities or determining the next turn in talk. The students' autonomy is ignored through the unequal power relation in Iran's language classrooms. In such a formal setting, based on the politeness theory, since the requests threaten teacher' negative face, students are expected to express their requests in a polite, formal and indirect way through long sentences as an attempt to save the negative face.

Research Question

The question is that to what extent data from the email requests of an Iranian student community confirms politeness theory?

and what are the politeness strategies used by EFL students in their email requests?

\section{METHODOLOGY}

The participants of this study were twenty-one female Iranian learners of English as a foreign language. Their English proficiency could be classified at intermediate level and their age ranged from 17 to 26 years old. The study was carried out during the students' regular English classes in Farzaneh English Institute, where the researcher conducted the study during the summer 2009.

There was a session of email discussion for the students, leading to cultural and pragmatic awareness raising. Following their textbook, the students were assigned an activity to email a common request that they make, to the researcher who was also their teacher, in an appropriate and polite form. The topic and the number of the request were not specified. As seen in Appendix A, an email discussion handout was compiled by the researcher. The email discussion includes eight pragmatic and cultural questions to be worked on in groups in class.

Considering the completely abstract nature of the task, the participants of the study tried their best. With the exception of one or two, they tried to imagine the context in which they felt the need to email a professor. For many individuals, the imagining part can be very difficult.

Since in Brown and Levinson's (1987) politeness theory, there is not any precise measure of politeness, Holtgraves and Yang's (1992) measure of politeness for email requests is used in this study. A coding scheme for politeness considers three factors: Formality of address phrase, degree of imposition and directness.

I. Formality of address phrase: the more formal the address phrase, the more polite the request

The greeting at the beginning of the email request is called address phrase which could be formal, informal or even absent. The use of appropriate titles such as Dr., Mr., etc., makes a formal address phrase. Informal address phrase consists of use of nicknames, first names, or inappropriate titles such as Prof., teach, doc, etc.

II. Degree of imposition: Highly imposing requests via email will be rated higher on measures of politeness.

In the following parts the features of email request with high and low degree of imposition are shown in order for the data to be analyzed.

- A request with low degree of imposition:

1. Getting attention

2. (Supportive sentences)

3. Requesting

4. Thanking

- A request with high degree of imposition:

1. Getting attention

2. (Small talk)

3. Supportive sentences

4. Requesting with modifications

5. Thanking

6. (Closing a conversation)

The following table mentions various types of supportive sentences along with their examples. The next explanation is related to modifications used to mitigate the effect of email requests. 
- Supportive Sentences:

\begin{tabular}{|l|l|}
\hline Supportive Sentence & Example \\
\hline $\begin{array}{l}\text { Ask the potential availability of the hearer or ask for the hearer's } \\
\text { permission to make the request. }\end{array}$ & $\begin{array}{l}\text { Are you busy right now? Do you have a minute? I have a question to ask you. } \\
\text { Could you do me a favor? }\end{array}$ \\
\hline Give a reason or an explanation for your request. & I missed class yesterday. Could you give me a handout? \\
\hline Promise a reward for the hearer if the request is carried out. & Could you give me a lift? I'll pay for the gas or take you out to dinner. \\
\hline $\begin{array}{l}\text { Reduce the imposition placed on the hearer by the speaker's } \\
\text { request. }\end{array}$ & $\begin{array}{l}\text { A: Maybe this weekend. B: This weekend works fine. Whatever works for } \\
\text { you. }\end{array}$ \\
\hline
\end{tabular}

- Modifications: The following words and phrases soften the force of the request.

a) Clean your room please.

b) Clean your room a little before dinner please.

c) Could you please lend me your book?

d) Do you think I could borrow your book?

e) Do you mind if I borrowed your book?

f) Would it be OK if you help me?

g) I was wondering if you could write it for me.

Based on Holtgraves and Yang's (1992) coding scheme, different types of direct and indirect strategies are shown in the tables below immediately following by similar tables which exemplify the students' data.

III. Directness: the use of indirect strategies is more polite.

\begin{tabular}{|c|c|}
\hline Direct Strategies & Example \\
\hline On record & Close the window. \\
\hline Giving an order with please & I would like to ask you to close the window please. \\
\hline Showing speaker's desire & I want you to close the window. \\
\hline Using Contractions and slangs & It's very kind of you if you can close the window. \\
\hline Direct Strategies & Example \\
\hline On record & So help me and I need your advice that pass it this course. \\
\hline Giving an order with please & please give me some suggest for my problem. \\
\hline Showing speaker's desire & so I like to request you some guidance to improve this skill, please. \\
\hline Using Contractions and slangs & $\begin{array}{l}\text { Because I'd like to be better speaker, introduce books about } \\
\text { conversations, please }\end{array}$ \\
\hline Indirect Strategies & Example \\
\hline Suggesting & How about closing the window? \\
\hline Asking about the hearer's ability & $\begin{array}{l}\text { Can/could/will/would you close the window? } \\
\text { Would you mind closing the window? }\end{array}$ \\
\hline Off record & You have left the window open... It's cold in here. \\
\hline No request & \\
\hline Indirect Strategies & Example \\
\hline Suggesting & What do you think about telling me more about final exam? \\
\hline Asking about the hearer's ability & would you please e-mail me that paper if it is possible for you. \\
\hline Off record & $\begin{array}{l}\text { I like to speak english well and I like to improve my Knowledge so I'm } \\
\text { so sad because I went to institute for two Years but I have lots of } \\
\text { problem in grammar. }\end{array}$ \\
\hline No request & \\
\hline
\end{tabular}

\section{DATA ANALYSIS}

Students' email requests are analyzed in this part. The parts in Italic are the analysis embedded in the original emails. There was no change made in the spelling or punctuation of the requests. The researcher did however change the color and size of the font. Some of the emails had pictures and signs (roses and hearts) attached to them which were deleted. Students' names are not mentioned in the study as they wish. Since the content of some emails are much the same as others, ten out of twenty-one emails are shown with their analysis following by the teacher's answers to the requests. (See the rest of emails in appendix B.) The subjects of emails were analyzed and the most frequent subjects were entitled as "request" or "a/the request". The following table shows the distribution of each subject:

\begin{tabular}{|l|l|l|l|l|}
\hline \multicolumn{1}{|l}{ THE DISTRIBUTION OF EMAIL SUBJECTS } \\
\hline Request & I need/want sth. & Please & Hello & Others \\
\hline $55 \%$ & $12 \%$ & $9 \%$ & $18 \%$ & $6 \%$ \\
\hline
\end{tabular}


1

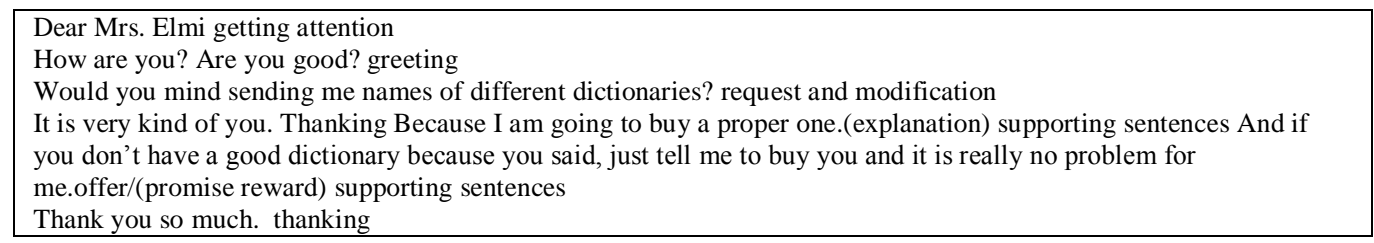

This request is short, to the point and easily understood. It is adequately polite, but not as polite as an obscure, drawnout request. The Address phrase is formal and the request was constructed through the use of two supportive sentences and two thanking. The request is accompanied by modification and is Asking about the hearer's ability. Therefore, the indirectness and the high degree of imposition show its high level of politeness.

Teacher's answer:

Dear student,

Thank you for your email. I would suggest LONGMAN Dictionary of contemporary English. The digital version including pronunciation, lots of examples, grammar lessons, exercises and writing assignments would be a great help to you in particular.

Kind Regards

2

Dear Miss. Elmi getting attention
Hello! How do you do? greeting
I hope have a good time.small talk I would love english language very much. (explanation) supporting
sentence I like to speak english well and I like to improve my knowledge so I am so sad beacuse I went to
institute for two years but I have lots of problem in grammar. (explanation) supporting sentence

It begins by attempting to establish a rapport with the recipient. However, its personal flavor is inappropriate for an academic request. On the other hand the use of supportive sentence and more importantly, the use of off record strategy demonstrate the degree of attempt to enhance the face with just giving a hint and not requesting. The address phrase is formal and the whole request is indirect and although there is not any thanking at the end, the degree of imposition is high. This request is considered a polite one.

Teacher's answer:

Dear student,

Thank you for your email. As your teacher I think that you do not practice what you are taught. Language learning is not all about interest. You need to work hard to get the accuracy you need.

Kind Regards

3

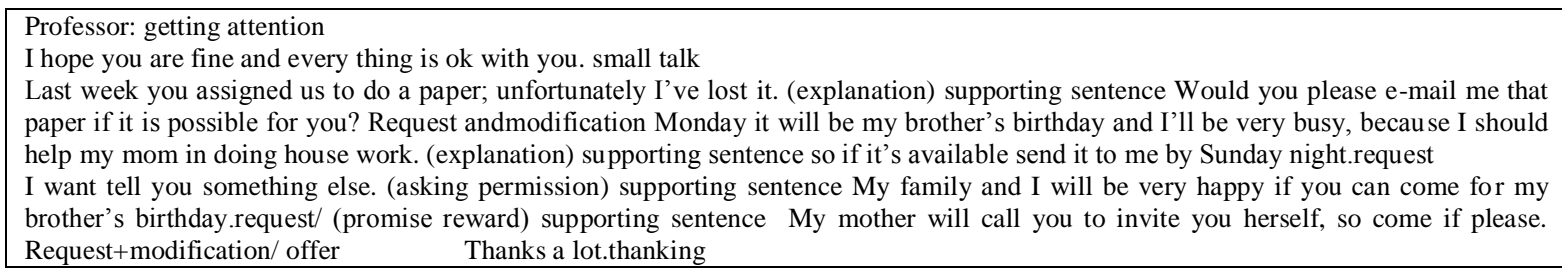

This student has too many excuses (which she describes in great detail) and two requests strung together in an email. Although there is a direct request showing speaker's desire in the email, it is accompanied by two other indirect ones asking about the hearer's ability. The address phrase is formal and the level of imposition is high. Therefore although the politeness is not that extensively high, the email is considered a polite one.

Teacher's answer:

Dear student,

Thank you for your email. I am attaching your assignment. I send my regards to your family.

Kind Regards

4

Hello professor. getting attention How do you do.greeting What do you think about telling me more about final exam.request+modification Can I request of you that fail lecture because it is very hard for me.

request+modification And I have busy mind. (explanation) supporting sentence

Because I'd like to be better speaker, introduce books about conversations, please. request+modification I very mistake the mean words and sometimes, I forget mean some words. (explanation) supporting sentence

Please give some suggest for my problem. request+modification 
This email shows the grammatical incompetency of this participant; however the grammatical errors are not our concern in this study. The first thing that comes to mind is the number of requests in this email: two direct request of giving an order with please and two indirect requests, one Asking about the hearer's ability and the other one suggesting. The request is accompanied by supportive sentences and the Address phrase is formal but there is not any thanking strategy at the end. With regard to the presence of direct requests, the request is not considered that polite on the scale of politeness, although the level of imposition is high.

Teacher's answer:

Dear student,

Thank you for your email. Your final exam has four parts of speaking (taken as oral exam), listening, reading and writing. The lecture would definitely be a part of final assessment. Focusing on your current text book would be the best. Regarding your difficulties in language learning, I prefer not to suggest any extra material.

Kind Regards

\section{5}

Dear teacher getting attention

Hello greeting

First, please excuse me since my mail became so late, because of some problem in my mailbox. (forgiveness) supporting sentence

Many of my classmates and I are poor in speaking skill. (explanation) supporting sentence so I like to request you some guidance to improve

this skill, please. request+modification

I would be glad if I can do anything for your favour regarding being a better student. (promiss) supporting sentence/offer

Your presence in our class is in great request,and make me so happy. small talk

This participant assures her teacher of how highly she regards the status of teacher and feels that complimenting a teacher in this way is not only acceptable, but will help her to acquire what she has requested. The sentences are well constructed containing supportive sentences of asking for forgiveness, promising and explanation. Thanking seems to be quite appropriate and the request comes with modification, thus the degree of imposition is high. The address phrase is formal but the request is of direct one Showing speaker's desire. Altogether the whole request is regarded a polite one.

Teacher's answer:

Dear student,

Thank you for your email. To improve your speaking skill, you need to expand your knowledge of vocabulary and grammar. Reinforcing the listening skill affect your speaking proficiency level as well. Reading questions and trying to answer them loudly would also be helpful.

Kind Regards

6

Hi teacher, getting attention

If you want me to improve give me some extra class and help me to improve. Please. request+modification

The imperative short style which reflects an order rather than a request would not be considered a polite request. No formal address phrase, no thanking and no supportive sentence cannot compensate for the presence of modification of please for the request. Therefore the imposition degree is low and the request is a direct one giving an order with please. The email request is not definitely regarded as a polite one.

Teacher's answer:

Dear student,

Thank you for your email. You do not need some extra class. You just have to study!

Kind Regards

7

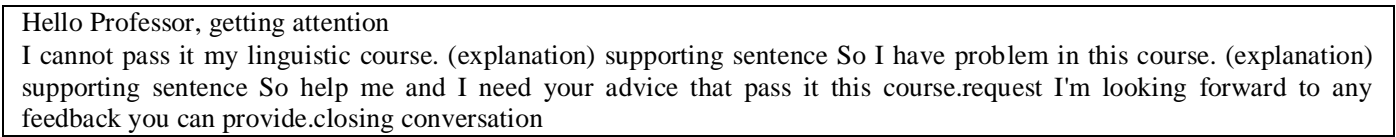

The sentences are short and clear. When speaking in Persian, this learner may be able to elaborate on issues more extensively. The reason of terseness may be the written form of the request, or it may be difficulties in trying to phrase her statements in English, in which case it goes back to the issue of essentiality of linguistic and grammatical competence as a basis for being polite. On the other hand, the request is of on record strategy without any modification and there is not any thanking feature. Therefore although address phrase is formal and the conversation is closed appropriately, the degree if imposition is low and also the request is a direct one. With regard to low degree of imposition and the directness of request, the politeness level is low.

Teacher's answer:

Dear student,

Thank you for your email. The one who can help you to pass the course is you. You have to believe in your capabilities and more importantly, you should study well and work hard to be successful. 


\section{Kind Regards}

8

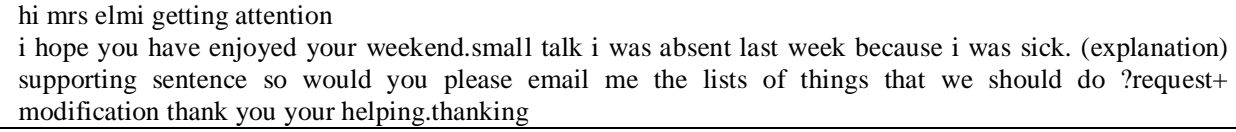

In this email request, the borderline of establishing a personal interest is the issue. Many learners do not attempt to establish a personal interest in fear of being rude. Others go overboard and seem inappropriate. The informal address phrase cannot fade the effect of small talk, proper thanking and the supportive sentence. The request is accompanied by a modification and therefore the degree of imposition is high. Besides, the indirect request of Asking about the hearer's ability, assures the politeness of the request.

Teacher's answer:

Dear student,

Thank you for your email. Last week we worked on the second part of grammar and finished the reading comprehension. You are supposed to do the exercises from page 56 to 60 and specifically, pay attention to your writing assignment.

\section{Kind Regards}

9

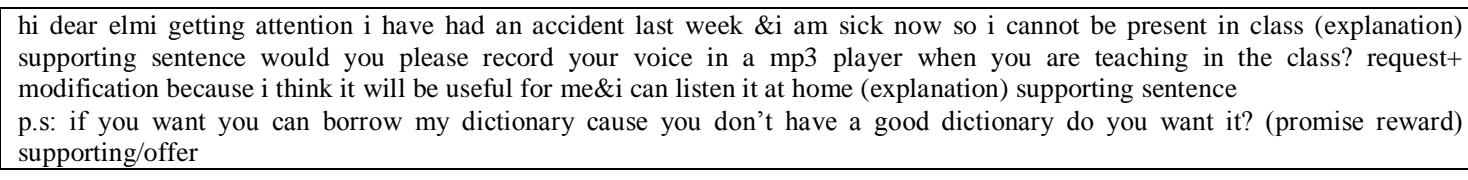

the first thing that comes to mind is that since this request is beyond the norm, it should be much more persuasive to be granted but the influential factors in determining politeness are degree of imposition and directness. The request comes with modification together with supportive sentences. The informal address and the absence of thanking are not extensively taken into consideration in determining the politeness level. The imposition degree is then high and the request is of indirect one Asking about the hearer's ability. The email request is considered polite.

Teacher's answer:

Dear student,

Thank you for your email and sorry for what happened to you. Regarding your request, I think you had better ask your friends and classmates to do so.

Kind Regards

10

Miss Elmi, getting attention
with best regards, small talk/greeting
I have very difficulty in speaking English and I like to speak better. (explanation) supporting sentence Would you help
me to speak it better? request+ modification and give me a guidance.request

"With best regards" after the getting attention phase is meaningless. That is not a polite beginning in an English email request. Referring back to participant's first language the transfer from Persian is obvious: The similar translation in the same part of letter. The request contains direct request of giving an order with please and indirect request of Asking about the hearer's ability. Although the address phrase is formal, there is no thanking and both criteria of imposition and directness are somewhere in the middle of measurement. Therefore the politeness level is in the middle of the scale.

Teacher's answer:

Dear student,

Thank you for your email. To improve your speaking skill, you need to expand your knowledge of vocabulary and grammar. Reinforcing the listening skill affect your speaking proficiency level as well. Reading questions and trying to answer them loudly would also be helpful.

Kind Regards

In the following table the formal address phrase with the distribution of $75 \%$ is the leading category.

THE FREQUENCY AND DISTRIBUTION OF ADDRESS PHRASES

\begin{tabular}{|l|l|l|}
\hline \multicolumn{2}{|l|}{ Address phrase } & absent \\
\hline Formal & Informal & 0 \\
\hline $75 \%$ & $25 \%$ & 0 \\
\hline
\end{tabular}


THE FREQUENCY AND DISTRIBUTION OF REQUEST STRATEGIES

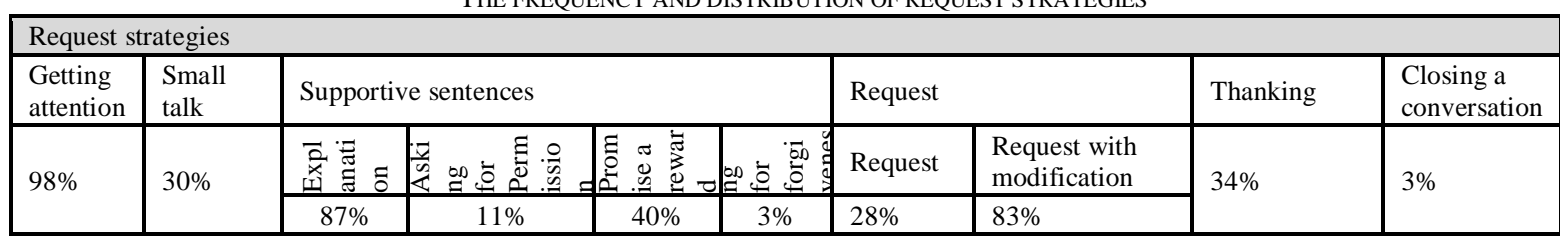

Regarding the politeness strategies used in students' requests, "getting attention" with distribution of $98 \%$ is the most frequent one following by "explanation" for the request as a supportive sentence. On the other hand, participants in this study have rarely closed an email request (3\% distribution).

Among the request strategies to be analyzed, "please" and "thank you" are not so culturally embedded in the Iranian culture as they are in western cultures, and the form of thanking isn't seen as explicitly as greetings; therefore, the rate of $72 \%$ usage of the politeness marker "please" is a large figure. This represents the transferability of pragmatic and politeness strategies.

In the Iranian culture saying greetings is considered very important. "Salam kardi?" "Did you say hello?" or "Did you say your greetings?" is asked repeatedly by parents trying to raise their children the proper way. One is to answer the greeting with a longer form of the greeting to be considered polite. The closest cultural equivalence to this in the west is 'please and thank you'. "What are the magic words?" parents remind their children to use these terms to be polite.

In Holtgraves and Yang's coding scheme, greeting is considered as equivalent to address phrase. Regarding the status of greeting in Iranian culture, in this study phrases such as "Hello. How are you?" are considered as a greeting. In some cases back-translation was needed to comprehend the greeting. In the last instance "with best regards" after "Miss Elmi" means nothing in English. It means "ba arze salam" in Farsi which is an expression used in that part of a letter on formal occasions. In the following table the frequency of three strategies of "please", "thanking" and "greeting" is demonstrated:

\begin{tabular}{|l|l|l|}
\hline Please & Thanking & Greeting \\
\hline $72 \%$ & $34 \%$ & $85 \%$ \\
\hline
\end{tabular}

\section{CONCLUSION}

Politeness theory proposed by Brown and Levinson (1987) is supposed to be universally valid for all cultures and languages. In this study the data from Iranian EFL students estimates if the theory is applicable to the participants' email requests. Holtgravesand Yang's (1992) coding scheme is the used criterion to analyze students' emails, addreessed to their teacher in a polite form. Measure of politeness for email requests considers three factors: formality of address phrase, degree of imposition and directness. Data analysis shows that most of the students expressed their requests in a polite, formal and indirect way although the analysis could be regarded as subjective.

Although in this study steps have been taken in determining patterns of usage of politeness strategies in email requests made by Iranian learners of English, Comments and questions regarding cultural and pragmatic factors concerning requests and also language competency of the participants should be taken into consideration. Despite the fact that in this study the focus was on pragmatic and politeness features and the researcher tried to overlook all grammatical, spelling and punctuation errors and kept in mind that the requests are coming from a foreigner, grammatical and pragmatic features are integrated and cannot really be separable in email request analysis.

\section{APPENDIX A: EMAIL DISCUSSION}

1. Should we ask how our professor is doing or feeling?

2. What is the appropriate address form in such an email?

3 . Should the email have a certain format?

4. What can you ask him/her to do and what can't you?

5. What tone should/shouldn't we take with our professor?

6. Should you set a deadline for him/her to finish our request?

7. Is there a difference in the words we choose when we email our professor?

8. Which pronoun is appropriate to use in our email: we or I?

9. Other group comments:

APPENDIX B: The Rest of EMAIL ReQuests

11

Dear miss elmi

How are you? 
I want ask is it ok if I hand my writing paper a week later? I had some problem in this week. That's very kind of you. Thank you and see you in class.

12

Hello Miss Elmi. I was sick last week and I dont feel very good this week so I can not come to class. I dont want miss some marks so $i$ ask if $i$ can do extra job to get the mark. Would you mind tell me what should i do? Tnx for your kindness.

13

dear teacher elmi

$\mathrm{i}$ am weak in conversation and i need help to improve my conversation and i should think when $\mathrm{i}$ want to say in english please give me guidance to better english conversation thank you very much

14

Dear Mrs. Elmi

I hope you are ok and every thing is good. My mother is a english teacher too but I can not work with her because I don't feel her a teacher and so I canot improv. would you please tell me guidance? I try to study every day but I fail.

15

Hello teacher how are you? Would you mind lend me your dictionary please? I need a dictionary but I can not buy it now. If you have a dvd dictionaty I can use it too. You are very kind.

16

Dear teacher Elmi

I am going to take a trip with my family next weak and I wonder if you can give me information about what are you going to teach when I am absent.

Thank you

17

Teacher elmi I have problem in talk and understand and I study at home but I am weak and have lot of problem, is it possible for you help me? please.

18

Daer teacher, how are you?

Thank you for all you do in our class. I think about the subject of final lecture and I am doubtful to select the topic. I wonder if you can provide me with some suggestions.

Thank you and have a good weekend.

19

Please I want to know how is final exam? How you measure? Can you tell me I can pass or fail?

20

Hello and good day

I wonder if you can inform me of any institute that is uniqe for ielts exam. I don't care about the fee and the place but I am going to study abroad and I need ielts degree to apply. I am good in speaking and listening but I need more practice. please informe me if you can.

\section{REFERENCES}

[1] Brown, P., \& Levinson, S. (1987). Politeness: Some Universals in Language Usage. Cambridge: Cambridge University Press.

[2] Chen, C.-F. E. (2001). Making E-mail requests to professors: Taiwanese vs. American students. Paper oresented at the Annual meeting of the American Association for Applied Linguistics (St. Louis, MO Febuary 2001).

[3] Cohen, A. D. (2004). The teaching of pragmatics in the EFL classroom. ILI Language Teaching Journal 3(2) , 1-28.

[4] Duthler, K. W. (2006). The politeness of requests made via email and voicemail: Support for the hyperpersonal model. Journal of Computer-Mediated Communication, 11(2), 6 .

[5] Ford, S. (2003). "The Instruction of Email Pragmatics to Second Language Learners". The 5th Annual Conference of the Japanese Society for Language Sciences, Conference Handbook , 126-131.

[6] Hartford, B. S., \& Barovi-Harlig, K. (1996). Experimental and Observational Data in the Study of Interlanguage Pragmatics. Pragmatics and Language Learning, 33-52.

[7] Holtgraves, T., \& Yang, J. (1992). Interpersonal underpinnings of request strategies: General principles and differences due to culture and gender. Journal of Personality and Social Psychology, 62 (2), 246-256

[8] Koutlaki, S.A. (2002). Offers and expressions of thanks as face enhancing acts: ta'arof in Persian. Journal of Pragmatics. 34 $1733-1756$

[9] Li, Y. (2000). Linguistic charactersistics of ESL writing in task-based e-mail activities. System (28), 229-245.

[10] Meloni, C., Gonglewski, M., \& Brant, J. (n.d.). Using E-mail in Foreign Language Teaching: Rationale and Suggestions. Retrieved from The Internet TESL Journal, Vol. VII, No. 3, March 2001 :

[11] Norris, J. M. (2001). Use of address terms on the German Speaking Test. In K. R. Rose, \& G. Kasper, Pragmatics in Language Teaching (pp. 248-282). Cambridge: Cambridge University Press.

[12] Schmidt, T. Y. (1994). Authenticity in ESL: a study of requests. Unpublished Masters Theses . 
Azadeh Elmianvari was born in Hamedan, Iran in 1982. She is currently the student of Advanced Master in Linguistics (Linguistics in a Comparative Perspective) at Gent University, Belgium. She has completed her Master degree in Teaching Engli sh as a Foreign Language(TEFL), at Allame Tabataba'i University in Tehran, Iran in 2009. Her BA is in English Literature from Alzahra University, Tehran, Iran in 2005.

From March, 2009 to June, 2011 she was a lecturer at three universities in Hamedan, Iran: BuAliSina University, Payame Noor University and Hamadan University of Technology.

Miss Elmianvari is planning to do her PhD at KULeuven, Belgium in the coming academic year in Applied Linguistics. Her main field of interest is the incorporation of technology in second/foreign language teaching.

Reza Kheirabadi was born in Tehran, Iran in 1979. He has just completed his PhD in General Linguistics at Tarbiat Modares University (Tehran, Iran) in 2012, and received his M.A. from the same university in 2006.He is now passing a 6 months scholarship in Gent, Belgium with News Text and Talk (NT\&T) Research Group.

$\mathrm{He}$ is currently working for Organization for Educational Research and Planning (OERP) which is the official body to prepare textbook materials and curriculum planning in Iran. He also has the experience of working for leading Iranian newspapers and news agencies as journalists and translator.

His main research interests are News production process, Language of News, Critical Discourse Analysis of news and ethnographic study of journalistic activities in Iran. His MA thesis was also about linguistic study of news values in press of Iran.

Dr. .Kheirabadi is a research assistant of NT\&T and a member of Public Relations Expert Association of Iran. 